\title{
Does Dispositionalism Entail Panpsychism?
}

\author{
Hedda Hassel Mørch
}

Forthcoming in Topoi, special issue on mental powers

Penultimate draft - please refer to published version for citation.

\begin{abstract}
According to recent arguments for panpsychism, all (or most) physical properties are dispositional, dispositions require categorical grounds, and the only categorical properties we know are phenomenal properties. Therefore, phenomenal properties can be posited as the categorical grounds of all (or most) physical properties - in order to solve the mind-body problem and/or in order avoid noumenalism about the grounds of the physical world. One challenge to this case comes from dispositionalism, which agrees that all physical properties are dispositional, but denies that dispositions require categorical grounds. In this paper, I propose that this challenge can be countered by the claim that the only (fundamentally) dispositional properties we know are phenomenal properties, in particular, phenomenal properties associated with agency, intention and/or motivation. Claims of this sort have been common in the history of philosophy, and have also been supported by a number of contemporary dispositionalists. I will defend a new and updated version of this claim, based on what I call the phenomenal powers view. Combined with other premises from the original case for panpsychism - which are not affected by the challenge from dispositionalism - it forms an argument that dispositionalism entails panpsychism.
\end{abstract}

\section{Introduction}

Panpsychism, the view that all physical entities are associated with phenomenal consciousness, has recently seen a revival in philosophy. This has been based on two main arguments. Both arguments start from the observation that all (or at least most) physical properties are dispositional. They then claim that dispositional properties require categorical grounds or realizers, and that phenomenal properties are the only categorical properties we know. This suggests that phenomenal 
properties could be the categorical realizers of all (or most) physical properties - as per what is known as Russellian panpsychism. ${ }^{1}$

The two main arguments then offer different reasons for taking this possibility as actual. The first main argument—call this the argument from philosophy of mind—claims that it enables a solution to the mind-body problem that avoids the main problems of physicalism and dualism at once (Strawson 2006; Alter and Nagasawa 2012; Chalmers 2013). Roughly, this is because, unlike physicalism, Russellian panpsychism takes phenomenal properties to be fundamental and irreducible to physical properties, but unlike dualism, it also offers phenomenal properties an explanatorily role in the physical world compatible with physical causal closure. The second main argument — call this the argument from anti-noumenalism—claims that Russellian panpsychism offers the only positive account of what the categorical grounds of physical dispositions might be, and thereby the only way of avoiding noumenalism, the Kantian view that the grounds of the physical world are unknowable or inconceivable (Strawson 2006; Seager 2006; Alter and Nagasawa 2012).

One challenge to both arguments comes from dispositionalism (Shoemaker 1980; Ellis 2002; Molnar 2003; Mumford 2004; Bird 2007). Dispositionalists agree with panpsychists that all (or most) physical properties are dispositional, but deny that they require any categorical grounds or realizers. Rather, they take dispositions to be fundamental and irreducible properties-roughly equivalent to non-Humean causal powers. This blocks the argument from philosophy of mind, by eliminating the need for categorical grounds, and thus the explanatory role that fundamental phenomenal properties are supposed to play. It also blocks the argument from anti-noumenalism,

\footnotetext{
${ }^{1}$ After Bertrand Russell, who offered an especially clear articulation of it (Russell 1927), even though he ended up endorsing neutral monism, a different but closely related view (see footnote 2 below).
} 
by implying that noumenalism can be avoided by eliminating categorical properties rather than conceiving of them as phenomenal. How can panpsychists respond to this challenge?

In this paper, I will first consider some of the main arguments that panpsychists have offered in defense of categoricalism, i.e., the view that dispositions require categorical grounds or realizers. I will conclude that these arguments cannot easily refute the challenge from dispositionalismsome because they only apply to other forms of non-categoricalism such as ontic structural realism (Ladyman and Ross 2007); others simply because they are not fully conclusive.

I will then propose that the challenge can rather be met by a different response, according to which dispositionalism may well be true. But the only fundamentally dispositional properties we know or can positively conceive of are phenomenal properties - in particular, phenomenal properties associated with agency, intention and/or motivation. Versions of this claim have been common in the history of philosophy, and have also been supported by a number of contemporary dispositionalists (and other realists about causal powers). I will defend a new and updated version of it. Combined with other premises which are already part of the previous arguments for panpsychism — and which are not affected by the challenge dispositionalism—-this forms an argument that dispositionalism entails panpsychism. ${ }^{2}$

\footnotetext{
${ }^{2}$ Note that Russellian panpsychism, the view that physical properties are realized by phenomenal properties, is a subspecies of Russellian monism, the view that physical properties are realized by non-physical properties which could be either phenomenal or protophenomenal/neutral (neither physical nor phenomenal). Some find non-panpsychist Russellian monism equally (if not more) capable of solving the mind-body problem and accounting for the categorical grounds of the physical world as the panpsychist version. But arguably, non-panpsychist Russellian monism comes too close to noumenalism to be compatible with the argument from anti-noumenalism, and is too reductive to be compatible with the argument from philosophy of mind. I will therefore set non-panpsychist Russellian monism aside in this paper. However, those who prefer some form of non-panpsychist Russellian monism to the panpsychist version are welcome to read this paper as supporting a response to the challenge from dispositionalism to parallel arguments against their view, according to which dispositionalism entails non-panpsychist Russellian monism - because the only fundamentally dispositional properties we know or can positively conceive of are neutral/protophenomenal properties (and perhaps also phenomenal properties, but they could be dismissed in view of arguments that support nonpanpsychist Russellian monism over panpsychism). However, this would require refuting my arguments below that
} 
I will begin by explaining the case for panpsychism from categorical properties in more detail (section 2). I will then discuss previous and potential defenses of categoricalism against the challenge from dispositionalism (section 3). I will then describe some of the recent and historical background for the argument for panpsychism from dispositional properties, before outlining my own version of it (section 4). Finally, I will offer a defense of this argument's central, novel premise: that the only fundamentally dispositional properties we know or can positively conceive of are phenomenal properties (sections 5 and 6). Claims of this sort have previously been defended by appeal to intentional or volitional properties (understood as causes of actions), but this defense faces difficult objections. I will therefore offer a different defense of the premise in terms of motivational phenomenal properties such as pain and pleasure (understood as causes of volitions), which I will argue avoids previous objections.

This defense will be based on what I have elsewhere called the phenomenal powers view. This is the view that phenomenal properties have (a priori knowable) causal powers in virtue of their phenomenal character, i.e., in virtue of how they feel (as opposed to in virtue of entering into contingent regularities or being governed by external laws). In other work, I have defended this view as a response to other problems of mental causation (Mørch 2018), and as part of an argument against physicalism (Mørch forthcoming-b). I have also previously examined the history and structure of arguments from dispositionalism (or realism about causal powers in general) to panpsychism (Mørch forthcoming-a) but here I defend my own version of it.

we have no positive concept of non-phenomenal, neutral powers (neither a primitive positive concept nor one that can be abstracted away from our experience of phenomenal powers). 


\section{The Case for Panpsychism}

Dispositions are properties that characterize what things $d o$, or properties that are essentially linked to the manifestation of particular further properties given particular circumstances or stimuli. For example, fragility is dispositional because it manifests as breaking in the circumstance of being struck. According to the case for panpsychism, all fundamental physical properties —with some possible exceptions such as purely spatiotemporal properties - are like this. Physical properties can be defined, roughly, as the kind of properties that can in principle be fully revealed by (completed, ideal) physics. ${ }^{3}$ And physics seems to reveal dispositions "all the way down" (Blackburn 1990). For example, all physics tells us about charge is that it is (roughly) the property of repelling entities with identical charge and attracting entities with opposite charge if (i.e., in the circumstance that) other charged entities are nearby. Similarly, all it tells us about mass is that it is (roughly) the property of resisting acceleration (if a force is present), attracting other massive entities, and so on.

Panpsychists then assert categoricalism: the view that dispositions require categorical grounds or realizers. Categorical properties can be defined as non-dispositional properties, or properties that are not essentially linked to the manifestation of any further properties. Defenses of categoricalism often presuppose that dispositions are purely relational or structural properties. This is based on the view that dispositions can be given a conditional analysis of the form "will $\mathrm{M}$ if $\mathrm{C}$ (given appropriate background qualifications ${ }^{4}$ )" (Ryle 1949; Lewis 1997), according to which

\footnotetext{
${ }^{3}$ In view of problems such as Hempel's dilemma, physical properties are also often defined negatively as (fundamentally) non-mental (see, e.g., Papineau 2001). But given the negative definition, it is not possible to distinguish physicalism from non-panpsychist Russellian monism (given that protophenomenal or neutral properties are also non-phenomenal and non-mental). I will therefore employ the positive definition in terms of physics, despite its problems.

${ }^{4}$ Such as the absence of finks, antidotes and other kinds of interference discussed in the literature (which may not be definable in non-dispositional terms, cf. footnote 18 below).
} 
dispositions consist in nothing more than relations between manifestations and circumstances. If these circumstances and manifestations are also dispositional and thereby relational, the physical world would reduce to a set of relations without (non-relational) relata, or a pure structure with no (non-structural) realizers. The claim that relations need (non-relational) relata is often put forth as self-evident.

But what could the categorical realizers of physical dispositions be, if physics does not tell us about them? Some suggest that these properties are unknowable, perhaps even inconceivable, similar to Kantian noumena. ${ }^{5}$ But according to panpsychists, phenomenal properties, i.e., properties that characterize what it is like to be in conscious states, are categorical. For example, consider the property of what it is like to see red. This property is associated with a number of dispositions, such as the disposition to verbally report seeing red if asked, or the physical dispositions of its neural correlate. But redness also has a phenomenal character which does not seem to consist in manifesting any further properties — a qualitative being that seems independent of its doing. The same seems to hold for other phenomenal properties. This suggests that phenomenal properties could be the categorical realizers of all physical properties — with the possible exception of purely spatiotemporal, and other relational but arguably non-dispositional, properties ${ }^{6}$ - by constituting the relata of all physical relations, as per Russellian panpsychism.

\footnotetext{
${ }^{5}$ At least on some readings of Kant, such as Langton (1998).

${ }^{6}$ Some relational properties such as spatiotemporal relations are arguably not purely dispositional, and if so, the arguments from categorical properties would not imply that they are phenomenal. This would still be compatible with panpsychism insofar as panpsychism primarily requires that all things in space and time are phenomenal, but not that space and time itself is phenomenal. More generally, panpsychism can be understood as the view that non-relational properties are all phenomenal, but there may also be relational properties that are not phenomenal or phenomenally grounded. The kind of panpsychism that allows for some fundamental non-phenomenal relations, such as spatiotemporal relations, is known as impure panpsychism. The kind of panpsychism that takes all properties including relations to be phenomenal or phenomenally grounded is known as pure panpsychism (Chalmers forthcoming).

One might think that if spatiotemporal relations are fundamental, then dispositions can be grounded in purely spatiotemporal relations rather than phenomenal properties. But even if spatiotemporal relations are fundamental, they
} 
The argument from philosophy of mind then claims that this view enables a solution to the mindbody problem that avoids the main problems of both physicalism and dualism (Strawson 2006; Alter and Nagasawa 2012; Chalmers 2013). The main problem of physicalism is the epistemic gap from physical to phenomenal properties (exemplified by, e.g., the knowledge gap (Jackson 1982) and the conceivability gap (Kripke 1980; Chalmers 1996)) which arguably should not be present if phenomenal properties were reducible to physical properties. Russellian panpsychism avoids this problem because it does not take phenomenal properties to be reducible to physical properties - rather, it takes physical properties to be (at least partially) reducible to phenomenal properties, in being categorically realized by them. The main problem of dualism is the problem of mental causation, according to which we have good reason to believe that the physical world is causally closed (Kim 1989; Papineau 2001). Therefore, if phenomenal properties are non-physical, they cannot causally affect the physical world (except as redundant overdeterminers). Russellian panpsychism avoids this problem because it gives phenomenal properties the explanatory role of categorically realizing, rather than causally interacting with, physical properties. This role is compatible with physical causal closure, and assuming we are not aware of any other kinds of categorical properties, phenomenal properties are not excluded from playing it.

The argument from anti-noumenalism, on the other hand, claims that phenomenal properties should be posited as the realizers of physical dispositions wholly independently of the mind-body problem, but rather in order to avoid the Kantian view that we have no knowledge or positive conception of the properties underlying the physical world (Strawson 2006; Seager 2006; Alter and Nagasawa 2012). According to this argument, phenomenal properties are not only the only

seem to require relata with non-spatiotemporal properties, otherwise they would not be capable of constituting a nonempty physical world, or a spacetime that is actually occupied by anything besides empty points or locations. 
categorical properties we know to exist, they are also the only categorical properties we can positively conceive of. A positive conception is a conception that lets the nature of a property be grasped or imagined in concrete or substantive detail. It contrasts with a merely negative conception that only specifies the metaphysical or theoretical role of a property (and leaves open how, or that in virtue of which, the role is played). Rejection of noumenalism is sometimes motivated by appeal to simplicity: when possible, we should prefer simple theories, and it is simpler to posit one fundamental kind of categorical properties (i.e., only the phenomenal kind) than two (i.e., both phenomenal and noumenal kinds) (Goff 2017). But it could also be motivated by a purely methodological principle, according to which we should not posit unknowable/inconceivable properties to satisfy our explanatory needs when an adequate positive alternative is available. This is a principle that we seem to adhere to in most other areas of inquiry, and should arguably therefore also apply to the question of categorical grounds (Mørch forthcoming-a). ${ }^{7}$

Both arguments can of course be challenged in a number of ways, ${ }^{8}$ but here I will only focus on the challenge from dispositionalism. As noted, dispositionalists agree with panpsychists that all (or most) physical properties are dispositional, but deny categoricalism, i.e., that dispositional properties require categorical realizers or grounds, because they take dispositions to be

\footnotetext{
${ }^{7}$ One problem with the appeal to simplicity is that noumenalists may claim that phenomenal properties are reducible to noumenal properties, which means that noumenalism also only posits one fundamental kind of categorical property and is therefore just as simple. The methodological motivation does not have this problem.

${ }^{8}$ The argument from philosophy of mind is mainly challenged by the combination problem, according to which panpsychism may account for how microphenomenal properties can be both fundamental and explanatory with respect to the physical world, but fails to account for our own macrophenomenal properties (Goff 2009; Chalmers 2016). The argument from anti-noumenalism can be challenged by arguments that we should expect the fundamental nature of the world to be unknowable and inconceivable in view of features of our cognitive constitution or overall epistemic situation (McGinn 1989), or by claims that we can positively conceive of categorical non-phenomenal properties on the basis of imagination, abstraction, or in accordance with primitive concepts (arguments that fundamentally dispositional properties can be positively conceived on this basis will be discussed below). Both arguments can also be challenged by the claim that phenomenal properties are not really categorical (as per reductive functionalism, phenomenal externalism and so on), or the claim that physics actually does tell us about categorical properties.
} 
fundamental. I will now consider whether this challenge can be refuted by arguments that have been, or could potentially be, put forth by panpsychists in defense of categoricalism.

\section{Defending Categoricalism}

\subsection{The Pythagorean Reductio}

In defense of categoricalism, a number of panpsychists (e.g., Seager 2006; Brüntrup 2011) have appealed to arguments against ontic structural realism (Ladyman and Ross 2007). Ontic structural realism is the view that all physical properties are purely structural or relational, but that relations do not need relata with non-relational properties; rather, physical relations can subsist on their own, or at least prior to their relata such that the relata are constituted by their position in a relational structure and would have no reality outside of it. ${ }^{9}$ Physical objects will thus be comparable to nodes in a graph, entities that have no properties except their position in the graph, or to numbers, which can arguably be exhaustively described in terms of their relations to other numbers. ${ }^{10}$

One of the most powerful arguments against ontic structural realism starts out from precisely the manner in which it renders physical objects comparable to mathematical objects: the view can be charged with collapsing the distinction between the physical and the mathematical, or the concrete and the abstract. Van Fraassen (2006) argues that "the difference between mathematical (uninstantiated) structure and physical (instantiated) structure cannot itself be explained in purely

\footnotetext{
${ }^{9}$ In this way, ontic structural realism avoids Newman's problem, according to which, unless physical relations have some qualitative or non-structural features, knowledge of physical relations reduces to knowledge of the mere cardinality of their relata (Demopoulos and Friedman 1985). This problem often comes up in the panpsychist literature as a response to various forms of structural realism (e.g., Seager 2006), but it presupposes that relata are prior to relations, which ontic structural realism denies (Ladyman and Ross 2007: 128).

${ }^{10}$ According to the structuralist conception of mathematics (Shapiro 1997).
} 
structural terms" (as paraphrased in Ladyman and Ross (2007: 158)). If the physical ends up being indistinguishable from the mathematical, the result is a kind of Pythagoreanism. For many, this would amount to a reductio ad absurdum.

But even if this or similar arguments against ontic structural realism were successful, it would not be sufficient to defend categoricalism against the challenge from dispositionalism. At best, it would establish a weaker claim:

Non-structuralism: All (or most) physical properties are realized by non-structural (i.e., non-relational) properties.

If dispositions were purely structural or relational, as per the conditional analysis, then categorical properties would be the only non-structural properties there are, and non-structuralism would imply:

Categoricalism: All (or most) physical properties are realized by categorical properties.

But unlike ontic structural realists, dispositionalists take dispositions to be fundamental and not reducible to either categorical or purely structural properties. Rather, they hold that dispositions should be regarded as irreducible, non-Humean powers (or other closely related properties such potencies or capacities). These powers have a relational aspect, in the sense that they are essentially directed or aimed toward producing their manifestations. For example, the power of charge is directed toward the repulsion/attraction of similarly/differently charged entities. But powers can also be thought of as characterized by a kind of primitive force or energy (or "oomph", as some have called it) that we may seem to have an intuitive, positive grasp of. This aspect is not purely structural or relational, at least not in the sense of being capturable in purely logicomathematical terms. The property of instantiating causal power has also traditionally been 
regarded as a paradigmatic criterion of real, concrete existence (for example by Plato's Eleatic Stranger). Dispositionalism thereby has a clear answer to the question of what distinguishes physical from mathematical structure, namely that the former is realized by powers. It is therefore not vulnerable to the Pythagorean reductio.

The view that all physical properties are fundamentally dispositional can be referred to as dispositional monism (Shoemaker 1980; Mumford 2004; Bird 2007). A closely related view is dispositional essentialism, according to which most physical properties are fundamentally dispositional, but some are categorical (Molnar 2003; Ellis 2002). Both these views constitute equal challenges to the case of Russellian panpsychism, because those physical properties dispositional essentialists tend to regard as categorical are the same properties that Russellian

panpsychists tend to regard as possibly primitive and non-phenomenal, such as purely spatiotemporal properties (see footnote 6 above). For this reason, I will use the term dispositionalism to refer to both dispositional monism and dispositional essentialism.

\subsection{Always Packing, Never Travelling}

Other panpsychists (e.g., Goff 2017: 140) have responded to the challenge from dispositionalism by appeal to the "always packing, never travelling"-argument, defended by Armstrong (among others). According to this argument, a world realized by powers alone would exist merely potentially, and not actually:

Can it be that everything is potency, and act is the mere shifting around of potencies? ... Given a purely Dispositionalist account of properties, particulars would seem to be always re-packing their bags as they change their properties, yet never taking a journey from potency to act. For 'act', on this view, is no more than a different potency. (Armstrong 1997) 
Or, as one might paraphrase the objection, the difference between an actual and a merely possible physical structure cannot be explained in terms of powers alone.

However, dispositionalists have responded that this objection conflates potencies and potentials:

... this view assumes that a power is a potential only and not at all actual in its own right: a power's actuality resides only in its manifestation. ... The danger of this view is that it treats powers as nothing more than mere potentialities but thereby ignores the obvious point that to be potent (as opposed to potential) is to be actual. On a causal criterion of existence ... being potent is the mark of being actual. Potent means powerful, which is something very different from being potential, meaning not yet actual. Those who favour powers regard them as potent rather than potential. Hence, while powers are powers to do or be other things, they are also things in their own right. The shifting round of potencies is acceptable, therefore, as long as there are actual things doing the shifting. (Mumford 2004: 174)

The significant difference between potencies and potentials, pointed out by Mumford, is that potentials are by definition not actual, whereas potencies (i.e., powers) could be regarded as actual without contradiction. Moreover, potency may even imply actuality, in accordance with the causal criterion of reality (as also mentioned above). In view of this defense, the "always packing, never travelling"-argument does not seem sufficient to refute dispositionalism.

\subsection{Intrinsicalism}

One might think the challenge from dispositionalism could still be refuted in a fairly simple way by shifting focus from categorical to intrinsic properties. The case for panpsychism is often presented in terms of intrinsic rather than categorical properties. An intrinsic property can be defined, roughly, as a property that is not constitutively dependent on the properties of other things. ${ }^{11}$ Categorical properties are constitutively independent of properties of other things,

\footnotetext{
${ }^{11}$ Though see Lewis and Langton (1998) for some further qualifications.
} 
including any circumstances and manifestations. Arguments that phenomenal properties are categorical would therefore also imply that they are intrinsic. Furthermore, the premise of categoricalism could be replaced with the more general premise of:

Intrinsicalism: All (or most) physical properties are realized by intrinsic properties.

One might think intrinsicalism is more easily defensible than categoricalism. Russell claimed that eliminating intrinsic properties leads to a vicious ontological regress whereby "all the things in the world will merely be each other's washing" (Russell 1927: 325). It has also been suggested that concreteness requires intrinsicality (perhaps because concreteness requires individuality which in turn requires intrinsicality). For example, Seager writes:

If relationalism [i.e., non-intrinsicalism] is true then no entity can exist by itself-all entities metaphysically imply the existence of other things, just as it is impossible for a node of a particular graph to exist apart from the rest of the graph. However, the evident difference between concrete individuals and the merely abstractly specified structures of graph theory (and other mathematical constructs) tells against relationalism here. What is concreteness, if not the ability of concrete things to exist apart from other things? (Seager 2006: 142)

But even granted that intrinsicality is required for concreteness or to avoid ontological regress, this would be no problem for dispositionalism, because powers can also be regarded as intrinsic. Given the conditional analysis, dispositions would be extrinsic because they are fully constituted by relations between external manifestations and circumstances. But when it comes to powers in the irreducible sense, it seems possible for them to exist unmanifested (see Molnar 2003). For example, it seems that a particle could have the power of charge, understood as involving a directedness toward the attraction or repulsion of other possible charged particles, even if it existed alone in the universe and this power could thereby never manifest as attraction or repulsion of any 
other actual charged particles. If this is correct, intrinsicalism is compatible with dispositionalism and could not be used to refute it.

\subsection{The Identity View}

Panpsychists could also consider appealing to arguments for the identity view of the categorical and the dispositional (Martin and Heil 1999; Strawson 2008). On this view, all properties are necessarily both dispositional and categorical, as opposed to purely one or the other. ${ }^{12}$ It has also been characterized as the view that all properties are powerful qualities, as opposed to pure qualities or pure powers. If the identity view is correct, dispositionalism entails categoricalism.

But even if the identity view could thereby save categoricalism, it would not save the overall case for panpsychism, because given the identity view, the challenge from dispositionalism to categoricalism would simply transform into an equally powerful challenge to the premise that the only categorical properties we know or can positively conceive of are phenomenal properties. If we have a positive grasp of dispositions as primitive, non-phenomenal powers, and these powers are also categorical, as per the identity view, it follows that we have a positive grasp of nonphenomenal categorical properties after all, contrary to this premise.

In this way, dispositionalism (including both pure dispositionalism and versions of the identity view that allow us to conceive of the categorical via the dispositional) seems to constitute a robust

\footnotetext{
${ }^{12}$ I have defined categorical properties as properties that are not essentially linked to the manifestation of any further properties and dispositional properties as properties that are essentially linked to the manifestation of further properties, given which the identity claim would seem contradictory. But identity view could perhaps be defined as the view that the essence of properties partially consists in being directed towards or otherwise linked to the manifestation of further properties, but also partially consists in some (at least conceptually) independent aspect or component, such as qualitativeness. This would distinguish the identity view from pure categoricalism, which could be defined as the view that the essence of properties not even partially consists in being linked to the manifestation of further properties, and pure dispositionalism, which could be defined as the view that the essence of properties fully and exhaustively consists in being linked to manifestations (and does not even partially consists in any independent aspect or component such as qualitativeness).
} 
challenge to the arguments for panpsychism from categorical properties, and there is no obvious way of defending categoricalism (including both pure categoricalism and versions of the identity view that do not allow us to conceive of the categorical via the dispositional) against it.

\section{Does Dispositionalism Entail Panpsychism?}

\subsection{Recent and Historical Background}

As we have seen, based on recent literature on panpsychism, panpsychism and dispositionalism might seem fundamentally opposed. However, in the literature on dispositionalism and causal powers, panpsychism often comes up in a surprisingly different way. Here, many philosophers see panpsychism, not as a potential consequence of rejecting dispositionalism in favor of categoricalism, but rather as a potential consequence of accepting dispositionalism. That is, panpsychism appears as part of an alleged reductio, a (supposedly "disastrous") consequence of accepting dispositionalism, along with realism about causal powers in general — the view that all things possess fundamentally dispositional properties, but may also possess categorical properties (in addition to those admitted by dispositional essentialists, such as purely spatiotemporal properties).

For example, Madden and Hare write:

It is most crucial to avoid what we like to call the "inferential predicament," because getting involved in it forces one inevitably into pan-psychism and animism, an unmitigated disaster in the eyes of a great majority of contemporary philosophers. ... The inferential predicament arises by taking volitional contexts as the only ones in which causal power is directly perceived, and then projecting such experienced power onto objects and events in order to make sense of causal necessities in the physical world. (Madden and Hare 1971: 23) 
Madden and Hare here claim that we seem to directly perceive causal powers in volitional contexts, i.e., when exerting our own efforts in agency. They warn that if these were our only experiences of causal power, we must take every instance of causation to involve the mental property of volition.

Martin and Pfeifer express a similar worry in terms of intentionality:

The most typical characterizations of intentionality ... all fail to distinguish intentional mental states from non-intentional dispositional physical states. Accepting any of these current accounts will be to take a quick road to panpsychism! (Martin and Pfeifer 1986: 531)

They add that: "for some, this may be a happy result—for us it is a reductio ad absurdum ..." (1986: 551). Similarly, Armstrong writes:

Consider, then, the critical case where the disposition is not manifested. The object still has within itself, essentially, a reference to the manifestation that did not occur. It points to a thing that does not exist. This must remind us of the intentionality of mental states and processes ... if irreducible dispositions and powers are admitted for physical things, then intentionality, irreducible intentionality, has turned up in everything there is. Is this not objectionable? Does it not assimilate the physical to the mental, rather than the other way around? (Armstrong 1997: 79, emphasis original)

Intentionality is the manner in which thoughts and mental states can be about or directed towards other things or states, and is regarded by many as a mark of the mental. Armstrong, Martin and Pfeifer point out how dispositionality and intentionality seem to share a number of essential features, such as directedness, and take this to suggest that everything dispositional is intentional.

Still, most realists about causal powers hold that panpsychism can be avoided. For example, Madden and Hare claim we experience causal power not only in volition but also in the physical world, whereas Martin and Pfeiffer offer a new account of intentionality that is not analogous with 
accounts of dispositionality. Others have accepted the analogy but denied that it entails panpsychism. For example, Place (1996) argues that intentionality is not a mark of the mental, but rather a mark of the dispositional. Similarly, Molnar (2003: ch. 3) argues that dispositionality is to be positively understood as a kind of "physical intentionality".

No contemporary panpsychists seem to have taken up the opportunity to defend panpsychism on the same basis, i.e., by defending both the analogy and the entailment. But historically, a number of panpsychists have made arguments of this kind (see Mørch forthcoming-a for details). For example, Leibniz repeatedly made claims such as:

The clearest idea of active power comes to us from the mind. So active power occurs only in things which are analogous to minds ... (Leibniz 1704/1981: 171)

Leibniz also held that everything fundamentally real has active power, from which it follows that everything fundamentally real is mindlike, as per his monadology.

William James also suggests (and later explicitly endorses (1912)) a similar argument:

... the concrete perceptual flux, taken just as it comes, offers in our own activity-situations perfectly comprehensible instances of causal agency ... If we took these experiences as the type of what actual causation is, we should have to ascribe to cases of causation outside of our life, to physical cases also, an inwardly experiential nature. In other words, we should have to espouse a so-called 'pan-psychic' philosophy. (James 1911: 218)

Similar arguments can also be found with panpsychists such as Schopenhauer (1859/1966), Whitehead (1933/1967: 184) and Hartshorne (1954).

There is also significant historical support for the alleged reductio. Several historical opponents of realism about causal powers have claimed that the concept of causal power is irredeemably 
anthropomorphic or animistic in virtue of being derived from experiences of will or motivation, and that realism about causal powers should therefore be rejected (see Hume 1748/1999: §52, fn 12; Mach 1897; Russell 1912; Collingwood 1937; Mørch forthcoming-a). They thereby endorsed the validity of the argument from dispositionalism to panpsychism, even though they denied its soundness.

\subsection{Parallel Arguments from Dispositional Properties}

Could there be an argument from dispositionalism to panpsychism that is at least valid? Assuming the original arguments from categorical properties are valid, it would seem so. The original arguments share the following two premises:

Categoricalism: All (or most) physical properties are realized by categorical properties.

Mental Categoricity: The only categorical properties we know or can positively conceive of are phenomenal properties.

Analogous premises can be constructed in terms of dispositional properties:

Dispositionalism: All (or most) physical properties are realized by fundamentally dispositional properties.

Mental Dispositionality: The only fundamentally dispositional properties we know or can positively conceive of are phenomenal properties.

By fundamentally dispositional properties, I here mean dispositional properties that are not in turn realized by categorical properties, as per categoricalism, ${ }^{13}$ nor realized by pure relations, as per

\footnotetext{
${ }^{13}$ The characterization of categoricalism could be understood as implicitly including the same fundamentality qualifier. But it seems widely assumed that categorical properties cannot be realized by dispositional properties, in which case the qualifier would be redundant.
} 
ontic structural realism. I will take fundamentally dispositional properties to include both purely dispositional properties and properties that are both categorical and dispositional, as per the identity view.

These premises could form the basis for an argument analogous to the original argument from philosophy of mind, according to which we should posit fundamentally dispositional phenomenal properties as the realizers of physical properties in order to give them an explanatory role and thereby solve the mind-body problem. They could also support an argument analogous to the argument from anti-noumenalism, according to which panpsychism offers the only way of avoiding noumenalism about the fundamentally dispositional grounds of the physical world.

If either of these arguments were sound, it would clearly disarm the challenge from dispositionalism to the case for panpsychism. But it might seem that this is not the kind of response that panpsychists would want to endorse because it would contradict the original arguments from categorical properties in important ways.

First, the claim that phenomenal properties are the only fundamentally dispositional properties we know might seem to contradict the original claim that all (or most) physical properties are dispositional. But this claim could be understood (and is often seemingly intended) as asserting that physical properties are dispositional in the non-fundamental sense of being reducible to relations between circumstances and manifestations. That is, the original claim can be understood as saying that physics reveals only purely relational or structural properties, ${ }^{14}$ but no intrinsic or non-relational properties of either the categorical or fundamentally dispositional kind.

\footnotetext{
${ }^{14}$ This might not seem like much for physics to reveal. But relational properties may include not only logicomathematical properties, but also irreducibly spatiotemporal properties and perhaps other fundamental relations (as long as these relations are still such as to arguably require intrinsic/non-relational relata, the role of which can be
} 
Second, the claim that phenomenal properties are dispositional might seem to contradict the original claim that phenomenal properties are categorical. But these two claims are not necessarily contradictory either, because according to the identity view, as discussed above, phenomenal properties may be both categorical and dispositional. But what if the identity view were shown to be incoherent ${ }^{15}$ or otherwise proven false? If so, then even though panpsychists who endorsed the original case from categorical properties would have been wrong to say that phenomenal properties are categorical, they would still have been right to say that phenomenal properties are intrinsic (given that both categorical and fundamentally dispositional properties are intrinsic). Their mistake might therefore only have consisted in conflating the notions of categoricity and intrinsicality, which is arguably not a very radical mistake because the distinction between these notions is quite subtle.

The arguments from dispositional properties could therefore be endorsed by proponents of the original arguments from categorical properties without contradiction, if they only admit that the original arguments contain at best some ambiguity or at worst a non-radical mistake.

I will now argue that the arguments from dispositional properties may actually be sound. This defense will be offered specifically as a response to the challenge from dispositionalism to the original arguments from categorical properties. In this context, only the Mental Dispositionality claim needs to be defended, because the other parts of the arguments are either (1) implied by dispositionalism ${ }^{16}$ and the Mental Dispositionality premise or (2) identical to parts of the original

occupied by phenomenal properties) (see footnote 7). And according to structural realism, an influential position in philosophy of science motivated entirely independently of panpsychism (and which comes in both an ontic and a less radical epistemic version compatible with panpsychism (see, e.g., Maxwell (1971)), structural knowledge adequately accounts for our knowledge of the physical world.

${ }^{15}$ For example, in view of the sort of problem noted in footnote 12 above.

${ }^{16}$ The challenge from dispositionalism obviously presupposes that dispositionalism is true. This does not imply the premise labelled Dispositionalism above, which expresses a more restricted version of dispositionalism according to 
arguments that are unaffected by the challenge. In particular, both the original case for antinoumenalism about the realizers of physical properties and the original case that positing phenomenal properties as the realizers of physical properties solves the mind-body problem are neutral on whether the realizers are categorical or dispositional, and are therefore not affected by the challenge. If these parts of the original arguments from categorical properties are sound, the corresponding parts of the analogous arguments from dispositional properties would also be.

I will defend Mental Dispositionality in two steps. First, I will argue that some phenomenal properties are, or can be positively conceived of as, fundamentally dispositional. Second, I will argue that phenomenal properties are the only fundamentally dispositional properties we know or have a positive conception of, because no physical or other non-phenomenal properties qualify.

\section{Defending Mental Dispositionality}

\subsection{Marks of the Dispositional}

What are the marks or essential characteristics of fundamental dispositionality? As noted, fundamental dispositions can be understood as roughly equivalent to non-Humean causal powers. Non-Humean causal powers (henceforth mainly referred to as just powers) are properties in virtue of which causes produce or bringing about their effects, or make them happen, and thereby metaphysically necessitate them. ${ }^{17}$ This distinguishes dispositionalism and other forms of realism

which physical properties are realized by, but not identical to, fundamentally dispositional properties. Dispositionalism broadly construed may take physical properties to be identical to fundamentally dispositional properties (i.e., take such properties to be directly revealed by physics). In the context of the present argument, the claim that physical properties are not identical to (and thus rather realized by) fundamentally dispositional properties follows from Mental Dispositionality, according to which the only fundamentally dispositional properties we know or can positively conceive of are phenomenal, and the fact that physics does not include phenomenal properties as fundamental.

${ }^{17}$ At least in the case of deterministic causation. Some hold that causation need not involve necessitation because causation can be indeterministic. But it seems indeterministic powers should still necessitate an increase in the objective probability of their effects occurring. I will set indeterminism aside for the sake of simplicity, but most of 
about causal powers from the regularity theory of causation (Hume 1739-40/2000; Lewis 1973), according to which causes are merely contingently followed by their effects. Powers should also, as discussed, be understood as intrinsic properties. This further distinguishes realism about causal powers from the governing laws view of causation (Armstrong 1978), according to which causes also necessitate their effects, but in virtue of being connected to them by irreducible laws that are extrinsic to the entities they govern. It should also be noted that powers are characteristically defeasible: powers only necessitate their effects in absence of interference from other powers (i.e., ceteris absentibus). ${ }^{18}$

How could powers be experienced or positively conceived of? Hume of course claimed that a true experience or conception of causal powers should present causes as inconceivable without their effects. He also claimed that all causes are in fact conceivable without their effects-for example, we can conceive of one billiard ball colliding with another, but the second one does not move. Many realists about causal powers have criticized this conceivability criterion as too strong. But it is hard to deny that the criterion would be sufficient - at least if we are talking about ideal inconceivability, understood as inconceivability by an ideally rational subject who is fully acquainted with the nature of the items she is conceiving of.

Perhaps there could also be other criteria for experiences or conceptions of causal powers that are weaker or less demanding, but still sufficient, so that the conceivability criterion would not be necessary. But supposing some phenomenal properties actually did satisfy the conceivability

the discussion to follow could be translated to apply to indeterministic views, e.g., instead of claiming that a cause is inconceivable without an effect, one could claim it is inconceivable without some objective probability its effect.

${ }^{18}$ It might be complained that the claim "A necessitates B ceteris absentibus" reduces to the truism "A is followed by B except when it isn't". This might be a problem for reductive analyses of powers, which are committed to defining interference in non-dispositional terms. But if dispositions are irreducible, as per dispositionalism, interference can be defined in terms of other dispositions or powers, as in "A necessitates B when there are no other powers directed at non-B", which is not a truism. 
criterion, but no physical properties satisfied it, then even if physical properties still were to satisfy some weaker criterion, it would seem reasonable to conclude that our experiences or conceptions of physical powers are not as revelatory as our experiences or concepts of phenomenal powers. That is, if phenomenal properties satisfy the conceivability criterion but physical properties do not, then the physical concepts/experiences should at the very least not be taken to afford us complete insight into the nature of dispositionality, given that the kind of insight that enables us to recognize necessity by means of inconceivability is in fact available in the phenomenal case. And if our conception of physical dispositionality is incomplete, then it must have some hidden aspect, which panpsychists may argue is phenomenal (in order to avoid noumenalism or allow phenomenal properties an explanatory role, as before).

Could any mental properties satisfy the conceivability criterion? As seen above, many philosophers considering the possibility of mental powers have focused on volitions, i.e., our own efforts or attempts at action. Hume considered this proposal at length, and argued that volitions and successful actions can conceivably come apart in the case of both physical and mental action, just as clearly as physical causes can conceivably come apart from their effects. This seems correct. For example, we can easily conceive of someone trying to move their arm, but no movement follows. We can also conceive of someone trying to calculate a sum, or recall a memory, but with no result (even stipulating the absence of interference). The same seems to hold for any mental properties that are intentional in some broader sense (such as thoughts, attitudes, prior intentions and so on) - they are also conceivable without their effects.

But there are also other mental properties besides volitional and intentional properties which seem dispositional, namely motivational phenomenal properties such as pain and pleasure. These are 
properties which Hume did not consider, and which I will now argue may actually pass the conceivability criterion.

\subsection{Motivational Phenomenal Properties}

Pain and pleasure appear to cause their effects in a distinctively dispositional or powerful way. Intuitively, pain seems to make subjects who experience it try to avoid it, whereas pleasure seems to make them try to pursue it. It is also difficult to conceive of pain and pleasure producing different, and especially opposite effects, i.e., pain making someone try to pursue it, or pleasure making someone try to avoid it. Note that the immediate effects of pain and pleasure are mere volitions rather than successful actions, i.e., mere tryings or attempts at avoidance and pursuit respectively (understood as mental events). Therefore, even if it is fully conceivable that volitions come apart from their effects (i.e., the actions they are aimed at), it may still be inconceivable that motivational properties such as pain and pleasure come apart from their effects (i.e. the mere volitions they motivate).

Also note that, like all causal powers, the powers of pain and pleasure would only necessitate, and hence should only be inconceivable without, their effects in the absence of interference from other motives or reasons (i.e., ceteris absentibus). Otherwise, a necessary connection would be falsified by actual as well as merely conceivable cases. Take pain. People of course endure or pursue pain, and avoid pleasure, for all kinds of interfering reasons. For example, people may endure pain because they believe it will lead to less pain in the future (as when cleaning a wound). They may also pursue pain because it leads to a greater pleasure at the same time (as in masochism), or because they believe it to be morally right (as with self-punishment). But in the absence of any interfering motives, it seems pain always makes subjects try to avoid it, and difficult to conceive 
otherwise. ${ }^{19}$ Furthermore, when there are interfering factors causing subjects to, e.g., pursue pain (such as a simultaneous or expected greater pleasure) it would not really be the pain that that caused this, but rather the interfering factor.

Even so, one might think it is not impossible to conceive of pain and pleasure having different effects, only somewhat difficult or unnatural, and that we can still conceive of it if we really try. In response, it may be granted (at least for the sake of the argument) that it may be conceivable that pain is regularly contingently followed by something else than avoidance attempts (such as pursuit attempts, or indifference), as per the (Humean) regularity theory. It may also be conceivable that pain is necessarily connected to something else than avoidance attempts in virtue of being constrained by an external law, as per the (Armstrongian) governing laws view. But it does not seem conceivable that pain makes subjects try to do anything else than avoid it in virtue of its intrinsic character alone, as per dispositionalism-assuming the intrinsic character of pain is constituted by its phenomenal character, i.e., what it is like, or how it feels. ${ }^{20}$

\footnotetext{
${ }^{19}$ One possible exception is asymbolic pain which, as discussed by Grahek (2007), does not seems to make subjects try to avoid it even in the absence of any interfering motives. In other work (Mørch forthcoming-b, manuscript), I argue that this does not refute the phenomenal powers view because evidence suggests that asymbolic pain is phenomenologically different form normal pain. In this paper, I use the term pain to refer to phenomenologically normal pain and assume that it excludes asymbolic pain.

${ }^{20}$ Dispositionalists could reject the assumption that the intrinsic character of phenomenal properties is constituted by their phenomenal character, by disputing that phenomenal character exists at all or that it is intrinsic. But disputing this would constitute a distinct objection to the overall case for panpsychism different from the challenge from dispositionalism (given that dispositionalism is also fully compatible with phenomenal character existing and being intrinsic), which is outside the scope of this paper.

One might think dispositionalists would still reject the assumption that properties necessitate their effects in virtue of their intrinsic character. Rather, they would hold that they just brutely necessitate their effects, and that is all there is to them. But if dispositions consist merely in sets of brute necessitation relations it is hard to say what would be intrinsic about them, and relatedly, how dispositionalism differs from ontic structural realism. And in any case, the "in virtue of" interpretation should at least be regarded as a valid version of dispositionalism. If phenomenal properties are inconceivable without their effects given this version, it supports (if the arguments I will offer below are correct) that phenomenal properties are dispositional in the sense of this version.

Another worry is that dispositionalism may seem to imply that the intrinsic character of properties should be fully capturable by dispositional concepts, understood as concepts that that pick properties out only in terms of their effects or manifestations and circumstances. But according to Russellian panpsychism, phenomenal character cannot be captured in dispositional terms (if so, the epistemic gap from physical to phenomenal properties should be easily closable, assuming that dispositional descriptions qualify as physical descriptions). Therefore, to say that the intrinsic
} 
To support this, try to imagine a painful experience, such as stepping on a sharp nail, as vividly as possible in terms of how it feels. The phenomenal character of such an experience can only be described as intrinsically disagreeable and repulsive. How could such an experience make someone try do anything else than avoid it solely in virtue of feeling like that? Correspondingly, the phenomenal character of pleasure can only be described as intrinsically agreeable and attractive. How could it make subjects try to do anything else than try to pursue it solely in virtue of feeling like that? It seems someone who conceives of pain and pleasure as having different effects in virtue of how they feel must either not know (or fail to vividly imagine or remember) how they feel, or implicitly assume that their effects do not derive from how they feel. To assume that their effects do not derive from how they feel is equivalent to denying dispositionalism (about phenomenal properties) in favor of the governing laws view or the regularity theory, or alternatively, in favor of epiphenomenalism, the view that phenomenal properties have no effects at all (in the sense of any theory of causation).

This seems to show that pain and pleasure necessitate their effects assuming dispositionalism is true (and the absence of interference). But the precise significance of this might not be very obvious. Prima facie, it might seem to only reflect the analytic or tautological truth that if dispositionalism is true, then (by definition) all properties necessitate their actual effects. But the

character of phenomenal properties is constituted by their phenomenal character would be incompatible with either dispositionalism (assuming phenomenal character cannot be captured in dispositional terms) or Russellian monism (assuming it can be captured in dispositional terms). A further problem is that if phenomenal character could be fully captured in dispositional terms that pick it out in terms of its actual effects, it would follow trivially or analytically that it could not have different effects. And inconceivability in virtue of analyticity is not an indicator of causal necessity of the kind involved in fundamental dispositionality.

But dispositionalism does not imply that the intrinsic character of properties should be fully capturable by dispositional concepts (as defined above). First of all, if dispositions are regarded as that in virtue of which properties necessitate their effects, it would seem that concepts that only specify that they necessitate particular effects could not capture their full nature. Second, if the identity view is correct, dispositions should also have a categorical or qualitative aspect that should also not be capturable in dispositional terms. Non-dispositional concepts of phenomenal properties could therefore be regarded as capturing one or both of these aspects of the intrinsic character of phenomenal properties, assuming they are dispositional. 
inconceivability only depends on the general assumption that pain and pleasure necessitate some effects or other in virtue of their phenomenal character. This renders it inconceivable that they do not necessitate avoidance and pursuit attempts specifically. It is not analytically true that if pain and pleasure necessitate some effects, then they necessitate any particular effects such as avoidance or pursuit attempts.

But neither could it show that pain and pleasure actually necessitate their effects, given that it seems conceivable and thereby possible that the antecedent assumption of dispositionalism is false. What it does seem to show, though, is that we are able to understand how pain and pleasure would be capable of necessitating their effects, or what it is about them in virtue of which they would necessitate their effects, if they were to do so. Given that we have a positive conception of the phenomenal character of pain and pleasure, it also shows that we have a positive conception of that in virtue of which they would necessitate their effects. This is enough to support the Mental Dispositionality premise, i.e., the claim that some phenomenal properties are known to be or positively conceivable as fundamentally dispositional, by supporting the disjunct of positive conceivability.

Furthermore, in the context where this premise is part of a response to the challenge from dispositionalism, there is also support for the other disjunct that some phenomenal properties are known to be (as opposed to merely positively conceivable as) fundamentally dispositional. The challenge presupposes that dispositionalism is true, and from this it follows that pain and pleasure actually necessitate their effects in virtue of their phenomenal character.

One might object that the inconceivability must rely on implicitly considering pain under dispositional concepts, understood as concepts that pick them out in terms of their particular effects 
or manifestations, e.g., conceiving of pain as "the disposition of making subjects attempt avoidance" and pleasure as "the disposition of making subjects attempt pursuit". If so, their particular effects would follow analytically after all. ${ }^{21}$ Such an analytic connection would merely reflect a logical connection between our concepts of pain and pleasure and their effects, rather than a necessary connection between these properties themselves. Or alternatively, it may reflect a mere constitutive relation between dispositions and manifestations, implied by conceiving of dispositions as constituted by relations to particular manifestations, rather than a causal relation between dispositions and their manifestations conceived of as distinct properties.

But the conceivability also arises when conceiving of pain and pleasure under phenomenal concepts that pick them out demonstratively in terms of how they feel, or what they are like from the first-person perspective. Phenomenal concepts are not dispositional nor otherwise logically connected to concepts of any particular effects: there is no logical connection between the concept of "feeling like this" — when pointing to an occurrent experience, or vivid memory, of pain or pleasure - and the concept of an avoidance or pursuit attempt. ${ }^{22}$ But it still seems inconceivable that pain should cause anything else than avoidance attempts in virtue of feeling like this — and

\footnotetext{
${ }^{21}$ One might also think pain and pleasure must be conceived of in purely dispositional terms given dispositionalism, but as discussed in footnote 20 above, dispositionalism (or at least some versions of it) also allows that dispositions have (intrinsic and/or categorical) aspects that are not captured in dispositional terms (that pick them out by their effects and triggering circumstances alone), and in terms of which non-dispositional concepts could therefore successfully refer to them.

${ }^{22}$ Note that even if there is no logical connection between purely phenomenal concepts of pain and pleasure and their respective effects, there could still be a conceptual connection in a broader sense, because phenomenal concepts are arguably constituted by the phenomenal properties they refer to (or faint "Humean copies" thereof) (Chalmers 2010: 265-266, 272). If there is a necessary connection between pain and avoidance attempts, and the concept of pain is constituted by (a Humean copy of) pain, there will also be a necessary connection between the concept of pain and avoidance attempts. But this sort of conceptual connection presupposes a necessary causal connection between the properties themselves, and so cannot be used to explain the appearance of a causal connection away as merely conceptual.
} 
vice versa for pleasure. The inconceivability thereby supports that pain and pleasure necessitate their effects in a properly causal way, in virtue of their own phenomenal character. ${ }^{23}$

To summarize: it seems inconceivable that pain and pleasure fail to necessitate avoidance and pursuit attempts respectively, assuming they necessitate some effects in virtue of their intrinsic, phenomenal character. This inconceivability does not reflect a mere analytic truth: first, because the assumption that pain and pleasure necessitate some effects in virtue of their phenomenal character is logically compatible with them necessitating any particular effects; second, because the inconceivability also arises when conceiving of pain and pleasure in purely phenomenal terms that are not logically connected to the concepts of avoidance or pursuit attempts. The inconceivability therefore suggests that we can positively conceive of pain and pleasure as fundamentally dispositional, i.e., that we can understand in concrete, substantive detail how they would be capable of necessitating their effects. In the context of offering a response to the challenge from dispositionalism against the case for panpsychism, the assumption that these properties actually necessitate some effects in virtue of their intrinsic character, which the inconceivability depends on, can be taken for granted. This implies that they are actually and thus knowably fundamentally dispositional. ${ }^{24}$

\footnotetext{
${ }^{23}$ A related objection would be that the inconceivability must derive from implicitly assuming a kind of analytic functionalism about pain and pleasure, according to which they must be considered under functional concepts, which would also pick them out in terms of their effects, but without specifying that they must be produced in a dispositionalist way. But if the inconceivability also follows from conceiving pain and pleasure under phenomenal concepts, it refutes this objection as well, because phenomenal concepts are both non-dispositional and non-functional.

${ }^{24}$ At this point, one might wonder whether the same kind of argument could support that volitions (or other intentional properties) could also be known or positively conceived of as fundamentally dispositional — because it might seem harder to conceive of volitions coming apart from the actions they are directed given the assumption that they necessitate some effects in virtue of their phenomenal character. Perhaps, but such an argument would not be entirely analogous. First of all, it is more difficult to get a firm grasp of volitions in purely phenomenal, completely nondispositional or non-functional terms (that define them in terms of the particular actions they are aimed at) and thereby more difficult to demonstrate causal as opposed to merely analytic (or constitutive) necessity. Second, volitions are not universally recognized as phenomenal or even mental. As noted above, it has been denied that intentionality is a mark of the mental (but rather a mark of the dispositional), and one might think volitions are purely intentional and not phenomenal (although it has been argued that intentionality is essentially phenomenal, as per the so-called
} 


\subsection{Non-Phenomenal Properties}

To establish the Mental Dispositionality premise, it must also be shown that phenomenal properties are the only fundamentally dispositional properties we know or can positively conceive of. When it comes to non-phenomenal properties known from either everyday experience or physics, it seems they all fail the conceivability criterion. For example, it seems we can easily conceive of solid objects, such as two billiard balls, passing through each other on impact (rather than the first making the second one move), or negatively charged entities, such as two electrons, attracting each other (rather than repelling each other), even assuming dispositionalism is true (and the absence of interference).

One might object that, according to dispositionalism, solidity is a dispositional property that essentially manifests as not passing through other solid objects on impact, and negative charge is a dispositional property that essentially manifests as repulsion of other negative charged particles, and so on. Therefore, these scenarios are implicitly logically incoherent and hence inconceivable. But the scenarios would only be logically incoherent if solidity and charge are conceived of in dispositional terms, i.e., under concepts that pick them out in terms of their actual manifestations or effects. If solidity is conceived of under a non-dispositional concept that picks it out, for example, in terms of how it looks or feels, it would be fully logically coherent and conceivable

\footnotetext{
phenomenal intentionality thesis (see Bourget and Mendelovici 2016), and also that volition is necessarily accompanied by a distinct kind of phenomenology (Horgan et al. 2003; Ginet 1997)). In contrast, pain and pleasure are phenomenal properties, and even granted that intentionality may not be a mark of a mental, it is hard to deny that phenomenology is (and denying this would in any case be futile for the purpose of blocking an argument for panpsychism understood as the view the all things involve phenomenal properties, but not necessarily mental properties in any other sense). For these reasons, the Mental Dispositionality premise seems at least more easily defensible in terms of motivational properties and their relation to volitions than in terms of volitions and their relation to actions (or other intentional properties and their relations to their effects, which would have the same problems as volitions).
} 
that solid objects pass through other solid objects - even assuming that the property picked out in this way is (a posteriori) identical with some (unspecified) disposition.

When it comes to charge, however, we might not be in possession of any non-dispositional concept $^{25}$ that does not implicitly pick it out in terms of its manifestations or effects-because we might not have a way of picking out unobservable properties except in terms of the dispositional or theoretical role they are posited to play. But in that case-as well as in the case where solidity is conceived of in dispositional terms - the inconceivability would reflect a mere logical relation between concepts, or alternatively, a constitutive connection between a dispositional property, considered as constituted by relations to its particular effects, and its effects, rather than a causal connection between distinct properties.

According to the conceivability criterion-whose validity is confirmed by the fact that it can actually be satisfied (conditional on dispositionalism) by phenomenal properties - this would show that there are no physical fundamentally dispositional properties - in the strict sense of "physical" as being fully revealed by physics. ${ }^{26}$ But one might think there could still be non-phenomenal or neutral, i.e., neither physical nor phenomenal, fundamentally dispositional properties.

Could we form a positive conception of neutral dispositions or powers? Many hold that we have an innate, primitive concept of causal power that is prior to physical experience (perhaps in some broadly Kantian sense). But even if there is such a concept, it would not necessarily offer us a

\footnotetext{
${ }^{25}$ Or at least non-functional concept (discussed in footnote 23 above), which picks its out in terms of its effects or theoretical role, but without presupposing a dispositionalist ontology.

${ }^{26}$ It might seem extreme to conclude that fundamental dispositions would not be physical based on the conceivability criterion alone. But under the current strict definition of the physical as fully revealed by physics, it should not be that controversial, unless one takes the regularity theory and realism about laws to be incompatible with physics, i.e., directly refuted by the straightforward empirical discovery of irreducible causal powers. Also note that dispositions could still be physical by the other common definition of the physical as non-mental (see footnote 3) (though not positively conceivable as non-mental, if my arguments below are successful).
} 
grasp of the nature of any particular powers. When it comes to physical properties, as just argued, it seems conceivable that they have any particular power assuming that they have some power (again, unless conceived of in dispositional terms), and the assumption that they have some power could be understood in terms of a primitive concept of causal power. This can be taken to show that we have no positive conception of how any particular physical properties are capable of satisfying the primitive concept of power. The question for proponents of neutral powers, therefore, is not whether we have a primitive concept of causal power in general (i.e., the property of intrinsically necessitating one's effects, whatever they may be) that does not imply mentality. Rather, the question is whether there are any particular neutral properties that can be positively conceived of as necessitating any particular effects, in virtue of being inconceivable without some particular effects, assuming they satisfy the (perhaps) primitive concept of causal power.

It is already unclear whether we are able to positively conceive of any particular neutral properties of any sort (with the possible exception of purely structural or abstract properties), given that neutral properties are not revealed by physics (by their definition as non-physical). It may be suggested that we have innate, primitive concepts of them, but this is hard to demonstrate. It would be even harder to demonstrate that we have primitive concepts of particular properties that are not only neutral, but also necessarily connected to other particular properties.

One might think that we could derive a positive conception of neutral powers from our conception of phenomenal powers by abstracting away the phenomenal aspects of phenomenal powers. But it is unclear how this could work. In general, abstraction is an operation that yields abstract structure. Causal powers are concrete and intrinsic, and so could not be positively conceived of in abstract, structural terms. Alternatively, abstraction might be understood as a process of subtracting away inessential elements or aspects of things. But for phenomenal properties, it is 
hard to discern any non-phenomenal elements or aspects at all (besides structural ones). By abstracting away their phenomenal aspects, then, we would seem to be left only with a purely negative conception of "some properties that are not phenomenal, but necessitate particular effects in the same way phenomenal properties do", i.e., a conception that only specifies a theoretical role.

However, it has also been argued that phenomenal properties do have non-phenomenal elements or aspects. Coleman (2013) argues that phenomenal properties have a qualitative and a subjective component which can come apart. On this view, phenomenal properties consist of purely qualitative properties which are not necessarily experienced by a subject, but become experienced and thereby come to constitute a phenomenal property when entering into appropriate relations (along the lines of the Higher-Order Thought theory of consciousness). If the qualitative and subjective aspects of phenomenal properties can be distinguished in this or some other way, and subjectivity is necessary for phenomenality, then perhaps by abstracting away from the subjective, experienced aspect of pain and pleasure we can arrive at a positive conception of particular nonphenomenal powers as unexperienced versions of these qualities?

In response to this, some would deny that unexperienced qualities are positively or even coherently conceivable. But even granted (for the sake of the argument) that they are, they would not seem dispositional in the same way as experienced, phenomenal properties-because it does not seem inconceivable that unexperienced pain and pleasure should fail to motivate avoidance or pursuit attempts (in virtue of their intrinsic and qualitative, but not phenomenal, character). Rather, it seems fully conceivable - and perhaps even to be expected - that unexperienced qualities would just be ignored by their subjects or otherwise cause something else. Therefore, by abstracting away the subjective aspect of phenomenal properties from their qualitative aspect, one would also abstract away what allows us to positively conceive of them as powerful. 


\section{Further Objections}

\subsection{Perception of Dispositionality}

One might object that, even granted that our experiences of pain and pleasure are experiences of dispositionality, this does not imply the dispositionality itself is not phenomenal, because experiences of pain and pleasure can be understood as a kind of perception of dispositionality. In ordinary perception, a physical object, such as an apple, can be perceived via a phenomenal representation, such as a visual image of the apple, without this implying that the apple itself is phenomenal. In the same way, one might think dispositions can be perceived via pain and pleasure phenomenology without this implying that the dispositions themselves are phenomenal. Or, in the same way as perceivable physical objects can exist without actually being perceived, the dispositions associated with pain and pleasure can also exist unexperienced and unaccompanied by any phenomenology.

Note that this suggestion is different from the view that phenomenal properties have a subjective and a qualitative element, and that the qualitative element can be conceived of as powerful apart from the subjective one, as already discussed above. Here, the suggestion is that the entire phenomenal property, including both the qualitative and subjective aspects of it (if any such aspects are separable), comes apart from a wholly distinct dispositional property that the phenomenal property represents.

But this suggestion still faces a similar problem, namely that when we conceive of dispositionality via pain and pleasure, these phenomenal properties do not merely play the role of representing dispositionality. They are rather part of the content that is being represented, because the necessary connections between pain and pleasure and their effects seem to hold in virtue of their 
phenomenology, or because of how they feel. Their phenomenology thereby seems to instantiate or ground their dispositionality rather than merely represent it. Therefore, if they were no longer associated with phenomenology, they would no longer be associated with anything (positively conceivable as) dispositional. Unlike perceptual objects as we ordinarily conceive of them, the dispositionality of pain and pleasure would therefore be inseparable from the phenomenology by which we experience them.

\subsection{The Conceivability of No Powers}

I have argued that it is inconceivable that pain and pleasure fail to necessitate avoidance and pursuit attempts respectively, assuming they (intrinsically) necessitate some effects. But I have also granted (at least for the sake of the argument) that it may be conceivable that pain and pleasure do not (intrinsically) necessitate anything, i.e., that the regularity theory, the governing laws view or epiphenomenalism is true. If conceivability implies possibility, it follows that it is also possible that they do not necessitate anything. And one might think that if pain and pleasure necessitate their effects, they must necessarily necessitate them (i.e., necessitate them in all possible worlds).

One response to this problem is that it is only ideal conceivability, i.e., conceivability by an ideal reasoner who is fully acquainted with all relevant aspects of the items conceived of, that implies possibility, and it might not be ideally conceivable that pain and pleasure do not (intrinsically) necessitate anything. The fact that we can actually conceive of it must therefore mean that we either fail to reason ideally about pain and pleasure, or are not acquainted with all their relevant aspects. Both options seem coherent. On the one hand, it could be supposed that an ideal phenomenological reasoner would not be able to conceive of pain and pleasure having no powers while remaining phenomenally identical, or still feeling exactly the same. For example, perhaps on ideal phenomenological reflection the phenomenal painfulness or hurtfulness of pain is not 
conceivable except as a real power and thus pain could not ideally conceivably fail to cause avoidance attempts (ceteris absentibus) no matter what. On the other hand, it could be supposed that pain and pleasure have some non-phenomenal aspects to their nature that we are not fully acquainted with, and which determine whether they really necessitate their effects in the way they seem capable of. This part of their nature is only knowable indirectly from further arguments (such as general arguments for dispositionalism or realism about causal powers).

One might worry that admitting that we may not be fully acquainted with or able to reason ideally about phenomenal properties undermines the conceivability argument against physicalism (Kripke 1980; Chalmers 1996), an important component of the problem of the epistemic gap that is presupposed by the argument for panpsychism from philosophy of mind (including the present version in terms of dispositional properties). But it is coherent to suppose that we are fully acquainted with and/or able to reason ideally about those aspects of phenomenal properties that rule out that they are identifiable with physical properties, but at the same time not fully acquainted with and/or able to reason ideally about those aspects that imply that they are powerful.

\section{Summary and Conclusion}

The case for panpsychism, according to which phenomenal properties should be posited as the categorical grounds of physical dispositions - in order to solve the mind-body problem and/or in order to avoid noumenalism about the grounds of the physical world - faces a challenge from dispositionalism. According to dispositionalism, dispositions are irreducible powers with no need for categorical grounds. I have shown that this challenge cannot be easily refuted by arguments aimed at preserving categoricalism. But it could be countered by an argument that dispositionalism entails panpsychism. 
Such an argument may be based on the following two premises:

Dispositionalism: All (or most) physical properties are realized by fundamentally dispositional properties.

Mental Dispositionality: The only fundamentally dispositional properties we know or can positively conceive of are phenomenal properties.

These premises can be combined with premises from the original arguments from categorical properties to yield a parallel set of arguments from dispositional properties. First, a parallel argument from philosophy of mind, according to which positing phenomenal properties as the fundamentally dispositional realizers of physical properties (i.e., as the causal powers, or perhaps powerful qualities, that ground physical relations) gives them an explanatory role that is compatible with them being fundamental, does not violate physical causal closure, and does not imply overdetermination. Second, a parallel argument from anti-noumenalism, according to which the fundamentally dispositional properties we should take to realize physical properties can only be positively conceived of as phenomenal, and - for reasons of either simplicity or methodologywe should not posit properties that are not positively conceivable to play this role when panpsychism offers an adequate positive alternative.

I have offered a defense of Mental Dispositionality - the claim that phenomenal properties are the only fundamentally dispositional properties we know or can positively conceive of-according to which motivational phenomenal properties, such as pain and pleasure (conceived of in purely phenomenal, non-dispositional terms), cannot conceivably fail to cause their particular effects of avoidance or pursuit attempts respectively, assuming dispositionalism is true (and the absence of interference). I have argued that this shows that we can positively conceive of these phenomenal 
properties as fundamentally dispositional. Furthermore, the challenge from dispositionalism implies that the antecedent assumption of dispositionalism is true, from which it follows that these phenomenal properties are actually and thus knowably fundamentally dispositional.

I have also argued that no physical or otherwise non-phenomenal (i.e., neutral) properties are inconceivable without some particular effects even assuming dispositionalism is true. The conceivability criterion of causal necessity seems sufficient, and given that phenomenal properties do satisfy the conceivability criterion, it is hard to see why it should not be necessary also for nonphenomenal properties. If all this is correct, it establishes Mental Dispositionality.

For the dialectical purpose of refuting the challenge from dispositionalism, Mental Dispositionality is the only premise of the arguments from dispositionalism to panpsychism that needs to be defended, because the other premises already form part of the original case for panpsychism and are not challenged by dispositionalism. For an independent argument from dispositionalism to panpsychism, one would have to include a fuller defense of at least one of these further original premises, i.e., either the premise the only (or at least best) way of solving the mind-body problem is to posit phenomenal properties as the realizers of physical properties or the premise that the realizers of physical properties are not noumenal.

As noted, the view of phenomenal causation on the basis of which I have supported Mental Dispositionality, the phenomenal powers view, has implications for many other issues beyond this, which I explore in other work - along with further details and objections I have not gone into here. 


\section{Acknowledgements}

I would like to thank Sam Coleman, Sebastian Watzl, Philip Goff, David Chalmers, Andrew Lee, two anonymous referees, and participants at the conference "Panpsychism, Russellian monism and the Nature of the Physical" at the University of Oslo for comments on various versions of this paper. 


\section{Bibliography}

Alter, Torin, and Yujin Nagasawa. 2012. What Is Russellian Monism? Journal of Consciousness Studies 19 (9-10): 67-95.

Armstrong, David M. 1978. A Theory of Universals. Universals and Scientific Realism Vol. II. Cambridge University Press.

Armstrong, David M. 1997. A World of States of Affairs. Cambridge: Cambridge University Press. Bird, Alexander. 2007. Nature's Metaphysics: Laws and Properties. Oxford: Clarendon Press.

Blackburn, Simon W. 1990. Filling in Space. Analysis 50 (2): 62-65.

Bourget, David, and Angela Mendelovici. 2016. Phenomenal Intentionality. In The Stanford Encyclopedia of Philosophy, ed. E. N. Zalta. Spring 2016 ed. Available from: https://plato.stanford.edu/archives/spr2017/entries/phenomenal-intentionality/.

Brüntrup, Godehard. 2011. Panpsychism and Structural Realism. In The Mental as Fundamental. New Perspectives on Panpsychism, ed. M. Blamauer.

Chalmers, David. forthcoming. Idealism and the Mind-Body Problem. In The Routledge Handbook of Panpsychism, ed. W. Seager Routledge.

Chalmers, David J. 1996. The Conscious Mind: In Search of a Fundamental Theory. New York: Oxford University Press.

Chalmers, David J. 2010. The Content of Phenomenal Concepts. In The Character of Consciousness. New York: Oxford University Press.

Chalmers, David J. 2013. Panpsychism and Panprotopsychism. The Amherst Lecture in Philosophy 8 (1-35. ): Reprinted in Brüntrup and Jaskolla 2016.

Chalmers, David J. 2016. The Combination Problem for Panpsychism. In Panpsychism: Contemporary Perspectives, eds. G. Brüntrup and L. Jaskolla. Oxford: Oxford University Press.

Coleman, Sam. 2013. The Real Combination Problem: Panpsychism, Micro-Subjects, and Emergence. Erkenntnis.

Collingwood, R. G. 1937. On the So-Called Idea of Causation. Proceedings of the Aristotelian Society, New Series 38: 85-112.

Demopoulos, W, and M Friedman. 1985. Critical Notice: Bertrand Russell's the Analysis of Matter: Its Historical Context and Contemporary Interest. Philosophy of Science 52 (4): 621-639.

Ellis, Brian. 2002. The Philosophy of Nature: A Guide to the New Essentialism. McGill Queens University Press.

Ginet, Carl. 1997. Freedom, Responsibility, and Agency. The Journal of Ethics 1 (1): 85-98.

Goff, Philip. 2009. Why Panpsychism Doesn't Help Us Explain Consciousness. Dialectica 63 (3): 289-311.

Goff, Philip. 2017. Consciousness and Fundamental Reality. Oxford University Press.

Grahek, Nikola. 2007. Feeling Pain and Being in Pain. Cambridge, MA: MIT Press.

Hartshorne, Charles. 1954. Causal Necessities: An Alternative to Hume. The Philosophical Review 63 (4): 479-499.

Horgan, Terry, J. Tienson, and G. Graham. 2003. The Phenomenology of First-Person Agency. In Physicalism and Mental Causation: The Metaphysics of Mind and Action, eds. S. Walter and H.-D. Heckmann. Exeter: Imprint Academic.

Hume, David. 1739-40/2000. A Treatise of Human Nature. ed. J. Cottingham. Oxford: Oxford University Press. 
Hume, David. 1748/1999. An Inquiry Concerning Human Understanding. ed. T. L. Beauchamp. Oxford: Oxford University Press.

Jackson, Frank. 1982. Epiphenomenal Qualia. Philosophical Quarterly 32 (April): 127-136.

James, William. 1911. Some Problems of Philosophy: A Beginning of an Introduction to Philosophy. New York: Longmans, Green \& Co.

James, William. 1912. The Experience of Activity. In Essays in Radical Empiricism. New York, London, Bombay and Calcutta: Longmans, Green \& Co.

Kim, Jaegwon. 1989. The Myth of Non-Reductive Materialism. Proceedings and Addresses of the American Philosophical Association 63 (3): 31-47.

Kripke, Saul A. 1980. Naming and Necessity. Cambridge, MA: Harvard University Press.

Ladyman, James, and Don Ross. 2007. Every Thing Must Go: Metaphysics Naturalized. Oxford: Clarendon Press.

Langton, Rae. 1998. Kantian Humility: Our Ignorance of Things in Themselves. Oxford: Oxford University Press.

Leibniz, Gottfried Wilhelm. 1704/1981. New Essays on Human Understanding. Translated by P. Remnant and J. Bennett. eds. P. Remnant and J. Bennett. Cambridge/New York: Cambridge University Press.

Lewis, David. 1973. Causation. Journal of Philosophy 70 (17): 556-567.

Lewis, David. 1997. Finkish Dispositions. Philosophical Quarterly 47 (187): 143-158.

Lewis, David, and Rae Langton. 1998. Defining 'Intrinsic'. Philosophy and Phenomenological Research 58 (2): 333-345.

Mach, Ernst. 1897. Popular Scientific Lectures. Translated by T. J. McCormack. Chicago: The Open Court Publishing Company.

Madden, Edward H., and Peter H. Hare. 1971. The Powers That Be. Dialogue 10 (1): 12-31.

Martin, C. B., and John Heil. 1999. The Ontological Turn. Midwest Studies in Philosophy 23 (1): 34-60.

Martin, C. B., and Karl Pfeifer. 1986. Intentionality and the Non-Psychological. Philosophy and Phenomenological Research 46 (4): 531-554.

Maxwell, Grover. 1971. Structural Realism and the Meaning of Theoretical Terms. Minnesota Studies in the Philosophy of Science 4: 181-192.

McGinn, Colin. 1989. Can We Solve the Mind-Body Problem? Mind 98 (391): 349-366.

Molnar, George. 2003. Powers: A Study in Metaphysics. Oxford: Oxford University Press.

Mørch, Hedda Hassel. 2018. The Evolutionary Argument for Phenomenal Powers. Philosophical Perspectives 31 (1).

Mørch, Hedda Hassel. forthcoming-a. The Argument for Panpsychism from Experience of Causation. In Routledge Handbook of Panpsychism, ed. W. Seager Routledge.

Mørch, Hedda Hassel. forthcoming-b. Phenomenal Knowledge Why: The Explanatory Knowledge Argument against Physicalism. In The Knowledge Argument, ed. S. Coleman Cambridge University Press.

Mørch, Hedda Hassel. manuscript. Phenomenal Powers.

Mumford, Stephen. 2004. Laws in Nature. New York: Routledge.

Papineau, David. 2001. The Rise of Physicalism. In Physicalism and Its Discontents, eds. C. Gillett and B. Loewer. Cambridge: Cambridge University Press.

Place, Ullin T. 1996. Intentionality as the Mark of the Dispositional. Dialectica 50 (2): 91-120.

Russell, Bertrand. 1912. On the Notion of Cause. Proceedings of the Aristotelian Society 13: 1-26. Russell, Bertrand. 1927. The Analysis of Matter. London: Kegan Paul, Trench, Trubner \& Co. 
Ryle, Gilbert. 1949. The Concept of Mind. Hutchinson and Co.

Schopenhauer, Arthur. 1859/1966. The World as Will and Representation Vol. 1. Translated by E. F. J. Payne. New York: Dover.

Seager, William. 2006. The 'Intrinsic Nature' Argument for Panpsychism. Journal of Consciousness Studies 13 (10-11): 129-145.

Shapiro, Stewart. 1997. Philosophy of Mathematics: Structure and Ontology. Oxford: Oxford University Press.

Shoemaker, Sydney. 1980. Causality and Properties. In Time and Cause: Essays Presented to Richard Taylor, ed. P. van Inwagen. Dordrecht: Reidel.

Strawson, Galen. 2006. Realistic Monism: Why Physicalism Entails Panpsychism. Journal of Consciousness Studies 13 (10-11): 3-31.

Strawson, Galen. 2008. The Identity of the Categorical and the Dispositional. Analysis 68 (4): 271282.

van Fraassen, Bas. 2006. Structure: Its Shadow and Substance. The British Journal for the Philosophy of Science 57: 275-307.

Whitehead, Alfred North. 1933/1967. Adventures of Ideas. New York: The Free Press. 